psychopathology via the child. This redefinition clarifies the roles of paediatricians and psychiatrists and is free of embedded assumptions.

1 Meadow R. Munchausen syndrome by proxy - the hinterland of child abuse. Lancet 1977; ii: 343-5.

2 Morris M. Munchausen's syndrome and factitious illness. Current Opinion in Psychiatry 1991; 4: 225-30.

3 Fisher GC, Mitchell I. Munchausen's syndrome by proxy factitious illness by proxy). Current Opinion in Psychiatry 1992; 5: 224-7.

4 Rosenberg DA. Web of deceit: a literature review of Munchausen syndrome by proxy. Child Abuse Negl 1987; 11: $547-63$.

5 Meadow R. Management of Munchausen syndrome by proxy. Arch Dis Child 1985; 60: 385-93.

6 Meadow R. Factitious illness - the hinterland of child abuse. Recent advances in paediatrics. Edinburgh: Churchill Livingstone, 1984: 217-32.

7 Jones JG, Butler HL, Hamilton B, et al. Munchausen syndrome by proxy. Child Abuse Negl 1986; 10: 33-40.

8 Meadow R. Munchausen syndrome by proxy. Arch Dis Child 1982; 57: 92-8.

9 Meadow R. Fictitious epilepsy. Lancet 1984; ii: 25-8.

10 Minford AMB. Child abuse presenting as apparent 'near miss' sudden infant death syndrome. BMF 1981; 282: 321 .

1 Rosen CL, Frost JD. Child abuse and recurrent infan apnoea. F Pediatr 1986; 109: 1065-7.

12 Mitchell I, Brummitt J, DeForest J, Fisher G. Apnoea and factitious illness (Munchausen syndrome) by proxy. Pediatrics 1993; 92: 810-4.

13 Clark GD, Key JD, Rutherford P, Bithoney WG. Munchausen's syndrome by proxy (child abuse) presenting as apparent autoerythrocyte sensitization syndrome: ing as apparent autoerythrocyte sensitization syndrome: an unusual prese

14 Malatack JJ, Wiener ES, Gartner JC, et al. Munchausen syndrome by proxy: a new complication of central venous catheterization. Pediatrics $1985 ; 75: 523-5$.

15 Ernst TN, Philp M. Severe iron deficiency. An example of covert child abuse (Munchausen by proxy). West $\mathcal{F}$ Med 1986; 144: 358-9.

16 Liston TE, Levine PL, Anderson C. Polymicrobial bacteremia due to Polle syndrome: the child abuse variant of Munchausen by proxy. Pediatrics 1983; 72: 211-3.

17 Kohl S, Pickering LK, Dupree E. Child abuse presenting as immunodeficiency disease. $\mathcal{F}$ Pediatr 1978; 93: 466-8.

18 Black D. The extended Munchausen syndrome: a family case. Br f Psychiatry 1981; 138: 466-9.

19 Lee DA. Munchausen syndrome by proxy in twins. Arch Dis Child 1979; 54: 646-7.
20 Alexander R, Smith W, Stevenson R. Serial Munchausen syndrome by proxy. Pediatrics $1990 ; 86$ : $581-5$.

21 Warner JC, Hathaway MJ. Allergic form of Meadow's syndrome (Munchausen by proxy). Arch Dis Child 1984; 59: 151-6.

22 McKinlay I. Munchausen's syndrome by proxy. BMF 1986; 293: 1308 .

23 Waller D, Eisenberg L. School refusal in childhood - a psychiatric-paediatric perspective. In: Hersov L, Berg I, eds. Out of school. Chichester: Wiley, 1980: 209-29.

24 Woollcott $\mathrm{P}$, Aceto T, Rutt C, et al. Doctor shopping with the child as proxy patient: a variant of child abuse. Behavioural Pediatrics 1982; 101: 297-301.

25 Keirn WC. Shopping parents: patient problem or professional problem. Ment Retard 1971; Aug: 6-7.

26 Schnaps Y, Frand M, Rotem Y, et al. The chemically abused child. Pediatrics 1981; 68: 119-21.

27 Verity CM, Winckworth C Burman D. Polle syndrome: children of Munchausen. BMF 1979; ii: 422-3.

28 Burman D, Stevens, D. Munchausen family. Lancet 1977 ii: 456.

29 Waller DA. Obstacles to the treatment of Munchausen by proxy syndrome. 7 Am Acad Child Adolesc Psychiatry 1983; 22: 80-5.

30 Libow JA, Schreier HA. Three forms of fractitious illness in children: when is it Munchausen syndrome by proxy? $A m$ f Orthopsychiatry 1986; 56: 602-11.

31 White ST. Surreptitious warfarin ingestion. Child Abuse Negl 1985; 9: 349-52.

32 Nicol AR, Eccles M. Psychotherapy for Munchausen syndrome by proxy. Arch Dis Child 1985; 60: 344-8.

33 Chan DA, Salcedo JR, Atkins DM, et al. Munchausen syndrome by proxy: a review and case study. $\mathcal{F}$ Pediatr Psychol 1986; 11: 71-80.

34 Atoynatan TH, O'Reilly E, Loin L. Munchausen syndrome by proxy. Child Psychiatry Hum Dev 1988; 19: 3-13.

35 Geelhoed GC, Pemberton PJ. SIDS, seizures of 'sophagea reflux? Another manifestation of Munchausen syndrome by proxy. Med F Aust 1985; 143: 357-8.

36 Masterton J, Dunworth R, Williams N. Extreme illness exaggeration in pediatric patients: a variant of Munchausen's by proxy? Am fु Orthopsychiatry 1988; 58: 188-95.

37 Eminson DM, Postlethwaite RJ. Factitious illness: recognition and management. Arch Dis Child 1992; 67: 1510-6.

38 Asher R. Munchausen's syndrome. Lancet 1951; i: 339-41. 39 American Psychiatric Association. Diagnostic and statistical manual of mental disorders. 3rd Ed, revised. (DSM-III-R.) Washington, DC: American Psychiatric Association, 1987.

40 Kaplan HI, Sadock BJ. Comprehensive textbook of psychiatry. 4th Ed. Baltimore: Williams and Wilkins, 1985: 591.
Department of Paediatrics and Child Health, St James's University Hospital, Leeds LS9 7TF

Correspondence to: Professor Meadow.

\section{What is, and what is not, 'Munchausen syndrome by proxy'?}

\author{
Roy Meadow
}

Flamboyant terminology has as many problems as advantages. 'Munchausen syndrome by proxy' was used originally for journalistic reasons. Munchausen syndrome was a commonly used term, applied to adults who presented themselves with false illness stories. ${ }^{1}$ Therefore it was plagiarised and adapted to apply to children who were presented with a false illness story invented by someone else (a proxy). ${ }^{2}$ While the introduction of the new term, in 1977, achieved its aim in leading to the recognition of many under recognised, ill described, and new forms of child abuse; its over use has led to confusion for the medical, social work, and legal professions. It has been used most in relation to fabricated illness of children which meets the following criteria:

(1) Illness in a child which is fabricated by a parent, or someone who is in loco parentis.

(2) The child is presented for medical assessment and care, usually persistently, often resulting in multiple medical procedures.
(3) The perpetrator denies the aetiology of the child's illness.

(4) Acute symptoms and signs of illness cease when the child is separated from the perpetrator.

As a diagnostic aid, these criteria lack specificity: many different occurrences fulfil them. It is common for children suffering physical or other forms of abuse to be presented repetitively for medical assessment, and for the perpetrating parent to deny that they have injured the child. It is common for such parent's actions to result in multiple medical procedures and, usually, the signs of injury abate when the child is separated from the perpetrator. Yet most of that abuse should not be classified as Munchausen syndrome by proxy.

\section{Historical background}

The original two index cases, for which the term was used, were memorable for particular 
reasons. They stood out because the mothers were so similar, even though their actions were so different. ${ }^{2}$ One mother had poisoned her child repetitively with salt from the age of 6 weeks until he died at the age of 15 months. The other mother had provided fictitious information about her child's urinary tract symptoms, and tampered with her urine samples to cause false results and innumerable investigations, operations, and treatment for her child in different medical centres. Both the mothers had an insatiable appetite for contact with good paediatric units, staffed with sympathetic doctors and nurses. The mothers seemed to get their gratification from the consequences of the child's illness upon their own life.

When the early cases were presented at the 1980 Annual Meeting of the British Paediatric Association, several paediatricians contacted me about other cases, and the cases they recalled were memorable to the paediatricians because of the mother's attitude and behaviour. The first large series of cases published (in this journal in 1982) was composed mainly of similar abuse - children who had incurred prolonged false illness caused by mothers who delighted in contact with paediatricians and paediatric units. ${ }^{3}$ However, in the last 10 years the label of Munchausen syndrome by proxy (synonyms: factitious illness by proxy, Meadow's syndrome) has been applied to a wide variety of abusive behaviour by parents simply because of the way that a parent has lied and deceived professional staff, or because of the weird, calculated, or manipulative way in which a parent has harmed a child. ${ }^{45}$

The need for clarity of the definition is not just for research studies; there are practical benefits. Currently the term Munchausen syndrome by proxy seems to cause great insecurity and panic among some of those who work with abused children. Secondly, those who have had most experience of extreme cases of induced illness, repetitive smothering and poisoning, ${ }^{67}$ recognise that many of the perpetrating parents share common characteristics and believe that they require approaches and help that are different to those used in the more common forms of child abuse. Therefore, without losing sight of the overall strategy for dealing with any form of child abuse, or the care that is needed to avoid incorrect allegations of abuse, it is appropriate to decide how to use the term Munchausen syndrome by proxy in a way that is helpful to child protection workers and, above all, to the children and families involved.

Though the term at first was used to describe a form of child abuse, rather than to describe a form of parental behaviour, most of the early cases were identified or recalled because of characteristic maternal behaviour, for instance mothers who thrived on a paediatric ward, formed close relationships with staff, and seemed less worried about their children than the doctors or nurses. ${ }^{3}$ Nevertheless colleagues in other professions, and frequently the perpetrators, have tended to talk about mothers who 'suffer from Munchausen syndrome by proxy'. Some of them have been over influenced by the media who, at the time of the trial of nurse Beverley Allitt (who was found guilty of four murders, three attempted murders, and six acts of grievous bodily harm to children on the paediatric ward in Grantham) described her as 'suffering from Munchausen syndrome by proxy. ${ }^{8}$ The media were confused by the fact that although Allitt, herself, could be said to have Munchausen syndrome, many of her actions to children had the characteristics of Munchausen syndrome by proxy abuse in that at times her primary purpose seemed to be to draw attention to herself rather than to kill or injure the child. In the past I have resented being asked in court whether someone is 'suffering from Munchausen syndrome by proxy': it has seemed no more appropriate than being asked if a man who has buggered his stepson is 'suffering from sex abuse'. However, relating the term to parental behaviour has some advantages, which is why it is appropriate to consider carefully the proposals in the Diagnostic and Statistical Manual of Mental Disorders (DSM IV) published by the American Psychiatric Association. ${ }^{9}$

\section{DSM IV proposals}

The task force and work group compiling the fourth edition of the manual considered proposals for a number of new categories and axes. As usual they decided that some of the new proposals needed further research before they could be included in the formal category of disorders. Munchausen syndrome by proxy, and its various synonyms, was one such new proposal. DSM IV prefers the term 'factitious disorder by proxy', and seeks to apply it to the perpetrator of the abuse, rather than to the abuse.

It suggests that the term might be applied to a person (the perpetrator) whose action fulfils the following criteria:

(A) Intentional production or feigning of physical or psychological signs or symptoms in another person who is under the individual's care.

(B) The motivation for the perpetrator's behaviour is to assume the sick role by proxy.

(C) External incentives for the behaviour (such as economic gain) are absent.

(D) The behaviour is not better accounted for by another mental disorder.

These criteria would allow the term to be used in circumstances other than child abuse - for instance in relation to persons who cause false illness in elderly, handicapped, or otherwise disabled adults, in their care. ${ }^{1011}$ Seemingly it would not be applied to those who cause false illness for their pets.

The key discriminator in that list is (B) - in relation to children, the mother would be harming the child (making the child ill) in order herself to assume the sick role and all its benefits. That is essentially the maternal behaviour that the early reports of Munchausen syndrome by proxy stressed. It also accords with the opinion that adults with Munchausen syndrome are addicted to the care that they receive from conscientious nurses and doctors, rather 
than to the investigations and painful treatments that ensue. ${ }^{12} 13$ They seek attention by using false symptoms, but do not necessarily appreciate the resultant procedures.

Current UK regulations demand that Munchausen syndrome by proxy abuse is categorised, on child protection registers, as 'physical injury'. ${ }^{14}$ However, although it often involves physical abuse, a more important and pervasive aspect is the associated and continuing emotional abuse. The DSM IV criteria would reinforce that, firstly by emphasising the perpetrator's motivation and, secondly, by the inclusion in criterion (A) of induction of psychological symptoms as well as physical.

The criteria will need study, debate, and alteration. It will be unwise to stick too closely to criterion $(\mathrm{C})$ - requiring external incentives, such as economic gain, to be absent. It is common for families to benefit economically, and in a number of other ways, as a result of making their child ill; even though in the first place the mother may have started inventing or causing illness in order to assume the sick role by proxy. A common result of secondary economic benefit is that it adds to the difficulty of altering maternal behaviour. ${ }^{15}$ Therefore criterion (C) is likely to need altering to allow incentives 'such as economic gain' to be present, providing that they were not the initial reason for the perpetrator's behaviour.

The advantage of limiting the use of Munchausen syndrome by proxy, or fi/actitious disorder by proxy, to those in which the perpetrators behaviour is motivated by the need to assume the sick role is that it will prevent the term being used for many forms of child abuse for which it is currently used inappropriately, some of which are described below.

\section{Not quite Munchausen syndrome by proxy}

\section{(1) UNRECOGNISED PHYSICAL ABUSE}

Young children who are presented, repetitively, with unusual burns in the mouth or marks on the skin, whose mothers deny injuring the child and lie about the circumstances of the injuries. Toddlers who are presented to hospital overdosed with drugs, given to them by a harassed mother trying to keep the child quiet. Mothers with feelings of hatred and violence to their children and those who suffocate their crying child to 'shut him up' or 'teach him a lesson'. The behaviour of these mothers to paediatricians and to hospitals is much more similar to that of other parents who injure their children. They are likely to be evasive and, at times, antagonistic to medical and nursing staff, not keen to spend time on the children's wards, and not at all in love with their paediatrician. ${ }^{16}$ Lying to cover up physical abuse is not Munchausen syndrome by proxy.

(2) FAILURE TO THRIVE AND/OR NEGLECT When a mother cannot cope or fails to feed the child adequately and lies about the circumstances. Money and Werlwas first used the phrase Munchausen syndrome by proxy (unknown to me at the time) in an article in relation to psychosocial dwarfism in which the parents starved and beat the children. ${ }^{17}$ However, most such parents are not seeking a sick role for themselves.

\section{(3) OVERANXIOUS PARENTS}

Parents whose extreme anxiety about their child's health or behaviour communicates itself to the child, thereby perpetuating and enhancing any adverse behaviour or ill health. Mothers who perceive symptoms out of fearfulness, or exaggerate symptoms to impress doctors. Impatient, over committed, and unsympathetic doctors may compound the problem.

\section{(4) MOTHERS WITH DELUSIONAL DISORDER ${ }^{18}$} They have convinced themselves of their child's illness or incapacity and cannot be dissuaded from their belief by appropriate investigation and careful explanation. At times the mother's behaviour is abusive to the child in its consequences because of restrictions she places on the child's life and the endless medical encounters she creates for the child. Most of these mothers do not get gratification from the child's 'illness'.

\section{(5) MASQUERADE SYNDROME ${ }^{19}$}

When a child is presented with repetitive illnesses, resulting in missing much time from school, and it emerges that the reason for the mother's behaviour is her wish to keep the child dependent on her, to keep herself in an active mothering role, and to prevent her child becoming independent and able to enjoy life's opportunities.

(6) HYSTERIA BY PROXY

When a mother believes herself to have an unusual illness, gross allergy, or incapacitating postviral syndrome and enforces that belief and behaviour on the child to make the child an invalid also.

\section{(7) DOCTOR SHOPPING ${ }^{20}$}

To seek a second or third opinion for a child may be sensible; to seek an 11th or 12th further opinion is likely to be abusive in terms of repeated investigation and needless procedures. However, most doctor shopping is done by parents who are either genuinely worried or deluded, and only a minority are doing it to assume the sick role for themselves. Moreover the parents seek the further opinions, whereas in Munchausen syndrome by proxy the paediatrician is usually the agent of referral. ${ }^{5}$

\section{(8) MOTHERING TO DEATH}

Mothers who, without involvement of doctors, treat their child as disabled or ill, confine them to bed or a wheelchair, or encase them in bandages until they die or are permanently disabled. These unusual and, hopefully, rare 
mothers seek to evade medical and social services. They cause illness and permanent harm to their child, but seem to be doing it more because of their need to adopt a perpetual mothering/nursing role for themselves rather than a sick role.

Many children abused in these different ways have come to light in the last decade partly because of people's awareness of Munchausen syndrome by proxy abuse, and their realisation that several of these forms of behaviour have links with it. While all the above forms of behaviour may be abusive to a child and may require interagency cooperation and the use of child protection procedures, that should happen without recourse to the term Munchausen syndrome by proxy for it confuses the issue. Moreover just because a mother has lied or deceived doctors, that in itself constitutes neither Munchausen syndrome by proxy, nor child abuse.

\section{A definition depending on motivation}

Confining the term, Munchausen syndrome by proxy, to those cases in which the motivation of the mother's behaviour is to assume the sick role for herself will not be easy, and much will depend on one's definition of 'the sick role'. It is likely to be necessary to include a number of different forms of attention seeking behaviour. It should allow the term to be used when the mother makes false allegations of abuse (whether physical or sexual) in order to gain attention for herself from child protection agencies. ${ }^{21}$ I doubt that it should be used for mothers who make false allegations of abuse, usually against a partner, in the context of divorce proceedings and custody disputes; there the motive is different - for instance to gain custody of the children or antagonise a former partner. ${ }^{22} 23$

Some believe that the behaviour of overambitious parents, who force their young children to train exhaustively in order to achieve excellence at sport, is a form of Munchausen syndrome by proxy abuse. They point out that many of the children hate that pressure and the different life that is imposed, and that the gratification comes to the parent and not the child. But the parent's gratification does not come by assuming the sick role: rather the reverse - the parent basks in the child's success and enjoys it more than the child (victor ludorum by proxy syndrome!).

I believe that it is helpful to distinguish between abuse (which may lead to the same end result for the child) being caused for widely different reasons. The area of suffocation and repetitive smothering is particularly pertinent. The main realisation that mothers smothered their children for many different reasons came from consideration of the spectrum of Munchausen syndrome by proxy abuse, ${ }^{24} 25$ and the polygraphic recording (including video surveillance) work of Rosen et al in America, ${ }^{26}$ which was carried on so constructively by Samuels and Southall et al in England ${ }^{27}$ and Stephenson in Scotland. ${ }^{28}$ Those with experience of large numbers of these cases recognise that, while some instances of smothering are akin to, and combined with, other physical abuse, a large proportion of the repetitive cases take place in the context of attention seeking behaviour by the mother. While the child has to be protected in all cases, the therapeutic approaches will vary greatly according to the circumstances and causes, which also have considerable prognostic importance in determining the safety of children within that parent's care. ${ }^{29}$ I have heard it argued that repetitive smothering in the context of Munchausen syndrome by proxy should not be considered a form of child abuse! Most will not agree with that - smothering represents severe abuse, whether the result of a violent mother 'shutting up' her crying baby, or a desperate, lonely, incapable mother creating apnoea to get herself and child into a caring hospital.

In the past, both DSM and the International Classification of Diseases have tended to avoid using motivation as a criterion in the classification of mental disorders, because of the inherent problems. It may be impossible at the time that the abuse is detected to be sure of the perpetrator's motive. By definition most of these mothers are accomplished deceivers and when the abuse is uncovered, many continue to deceive those who assess them. It is common for mothers, particular if they have read some of the medical literature, to allege that their behaviour was a 'cry for help', because of their own needs. They may be encouraged in that claim by their legal advisers, yet years later some of them admit to different motives, including feelings of hatred and violence to their child. ${ }^{25}$ Conclusions about the mother's motive, based merely on interviews with her, are fraught with problems and, even when great efforts are made to discuss the mother's behaviour with family members and with doctors and other professionals who have known the mother for a long time, it can still be difficult to judge the motive. Thus the key criterion, (B), comes either from consideration of the mother's disclosure in the light of her own past medical history, or from the subjective judgment of paediatricians or other doctors who have been dealing with the child's false illness. Moreover it may be rather simplistic to seek a single motivation. Complex behaviour is likely to result from complex motivation.

Eminson and Postlethwaite considered the various types of factitious illness and pointed out that serious abuse occurred according to the degree in which parents failed to distinguish their own needs from those of the child. ${ }^{30}$ Classical Munchausen syndrome by proxy abuse is such an example, for the mother is putting her own need (to be in the sickness role, or to receive attention), way ahead of the needs of her child. Similarly the parent who gives way to anger and physically injures the child, or the one who goes out to the pub and neglects the child, is putting their own need ahead of the child's.

\section{A label for the abuse, or a label for the perpetrator?}

While there may be some advantages in applying the term to the perpetrator, there are 
also dangers. Perpetrators do not like being considered to be suffering from Munchausen syndrome by proxy and I doubt that they will enjoy factitious disorder by proxy either. There is a danger that applying the term to the perpetrator, rather than to the abuse, will suggest that there is a single cause for the behaviour and a possible single remedy. Even with strict adherence to the criteria it will be found that many different sorts of people, men as well as women, behave in this way; psychosocial studies reveal different types of perpetrator. ${ }^{31}$

A major disadvantage of factitious disorder by proxy being applied to the perpetrator, rather than to the abuse, would be if it led to authorities believing that such abuse of children could be diagnosed by psychiatrists, or that an assessment of the perpetrating parent could overrule the clinical and forensic findings made by those involved with the child. Differentiating between natural illness and factitious illness can be extraordinarily difficult and requires the most careful and skilled clinical appraisal. That has to be by a person trained and experienced in the disorders of childhood, usually a paediatrician (preferably one with extensive experience of child abuse also). Assessment of the suspected perpetrator and family is most useful, but takes second place to the clinical appraisal of the child.

\section{Recommendations}

Because so many different forms of abusive behaviour by parents have been identified, and more will continue to be identified, it will be wisest to reserve the term Munchausen syndrome by proxy (or factitious disorder by proxy) for abuse in which the perpetrator is motivated by the need to assume either the sick role by proxy or another form of attention seeking behaviour.

My preference is for the term to be used to describe a form of abuse, rather than to be applied to a perpetrator. If, for professional contracts, or other reasons, other countries need a term to apply to the perpetrator, then factitious disorder by proxy is reasonable providing that those who do so realise the limitation of their diagnostic criteria, as well as the fact that the differentiation between factitious and genuine illness in the child has to be made by an experienced clinician and not merely by the expert assessing the parent.

Whatever term is used, and in whatever way, does not alter the fact that for an individual child who has been abused the most important thing is for the assessors to define accurately what has happened. Not only in cases of Munchausen syndrome by proxy abuse, but most other forms of abuse, it is more appropriate to list carefully the way in which a child has been abused, than to use a diffuse non-specific term. Munchausen syndrome by proxy abuse can be mild; it can be severe. Therefore a careful evaluation, detailing of injuries, and description of the way in which the individual child has suffered, or is likely to suffer, is paramount.

Whenever an abused child's future is being considered, and ways are being sought to help the family, the motivation of the perpetrator can be the key to understanding the abuse and formulating a policy for safe parenting and prevention of future harm. Limiting the term Munchausen syndrome by proxy to cases similar to those first described, in which the motivation of the perpetrator seems to be either the assumption of the sick role for themselves, or other attention seeking behaviour, is a useful way forward. The term is worth using if it allows formulation and trial of different management and therapeutic regimens for a more homogeneous group, and should lead to better understanding of parental behaviour and more effective help.

I am grateful to Mandy Jones for her patience, equanimity, and skilled assistance.

1 Asher R. Munchausen's syndrome. Lancet 1951; i: 339-41. 2 Meadow R. Munchausen syndrome by proxy: the hinterland of child abuse. Lancet 1977; ii: 343-5.

3 Meadow R. Munchausen syndrome by proxy. Arch Dis Child 1982; 57: 92-8.

4 Rosenberg DA. Web of deceit: a literature review of Munchausen syndrome by proxy. Child Abuse Negl 1987; 11: 547-63.

5 Meadow SR. Munchausen syndrome by proxy. fournal of Clinical Forensic Medicine 1994; 1: 121-7.

6 Rogers D, Tripp J, Bentovim A, Robinson A, Berry D, Goulding R. Non-accidental poisoning: an extended syndrome of child abuse. $B M \mathcal{F}$ 1976; i: 793-6.

7 Meadow R. Non-accidental salt poisoning. Arch Dis Child 1993; 68: 448-52.

8 The Allitt inquiry. London: HMSO, 1994.

9 American Psychiatric Association. Diagnostic and statistical manual of mental disorders. 4th Ed. (DSM IV.) Washington: American Psychiatric Association, 1994.

10 Smith NJ, Ardern MH. More in sickness than in health: a case study of Munchausen syndrome by proxy in the elderly. Fournal of Family Therapy 1989; 11: 321-4.

11 Sigal MD, Altmark D, Carmel I. Munchausen syndrome by adult proxy: a perpetrator abusing two adults. 7 Nerv Ment Dis 1986; 174: 696-8.

2 Ireland P, Sapira JD, Templeton B. Munchausen's syndrome. Am $\mathcal{f}$ Med 1967; 43: 579-92.

13 Cramer B, Gershberg MR, Stern M. Munchausen syndrome: its relationship to malingering, hysteria and the physicianits relationship to malingering, hysteria and the physician-

14 Department of Health. Children and young people on child protection registers year ending 31 March 1993; England. London: Department of Health, 1993.

15 Neale B, Bools C, Meadow SR. Problems in the assessment and management of Munchausen syndrome by proxy abuse. Children and Society 1991; 5: 324-33.

16 Schreier HA, Libow JA. Hurting for love, Munchausen by proxy syndrome. New York: Guilford Press, 1993.

17 Money J, Werlwas J. Folie a deux in the parents of psychosocial dwarfs: two cases. Bull Am Acad Psychiatry Law 1976; 4: 351-61.

18 Rogers ML. Delusional disorder and the evolution of mistaken sexual allegations in child custody cases. American fournal of Forensic Pathology 1992; 10: 47-69.

19 Waller D, Eisenberg L. School refusal in childhood - a psychiatric-paediatric perspective. In: Hersov L, Berg I, eds. chiatric-paediatric perspective. In: Hersov L, B

20 Woollcott $\mathrm{P}$, Aceto T, Rutt C, et al. Doctor shopping with the child as proxy patient: a variant of child abuse. the child as proxy patient:

21 Meadow R. False allegations of abuse and Munchausen syndrome by proxy. Arch Dis Child 1993; 68: 444-7.

22 Rand DC. Munchausen syndrome by proxy: integration of classic and contemporary types. Issues in Child Abuse Accusations 1990; 2: 83-9.

23 Heiman ML. Annotation: putting the puzzle together: validating allegations of child sexual abuse. 7 Child Psychol Psychiatry 1992; 33: 311-29.

24 Meadow R. Fictitious epilepsy. Lancet 1984; ii: $25-8$.

25 Meadow R. Suffocation, recurrent apnoea and sudden infant death. F Pediatr 1990; 117: 351-7.

26 Rosen CL, Frost JD, Bricker T, Tarnow JD, Gilette PC, Dunlavy $S$. Two siblings with recurrent cardiorespiratory Dunlavy. Tho siblings with recurrent cardiorespiratory Pediatrics 1983; 71: 715-20.

27 Samuels MP, McClaughlin W, Jacobson RR, Poets CF, Southall DP. Fourteen cases of imposed upper airways obstruction. Arch Dis Child 1992; 67: 162-70.

28 Stephenson JBP. Specific syncopes and anoxic seizure types. Fits and faints. Oxford: Mac Keith Press, 1990: types.

29 Bools CN, Neale BA, Meadow SR. Follow up of victims of fabricated illness (Munchausen syndrome by proxy). Arch Dis Child 1993; 69: 625-30.

30 Eminson DM, Postlethwaite RJ. Factitious illness: recognition and management. Arch Dis Child 1992; 67: 1510-6.

31 Bools C, Neale B, Meadow R. Munchausen syndrome by proxy. A study of psychopathology. Child Abuse Negl 1994; 18: 773-88. 